\title{
Apparatus for bisensory presentation of coded signals*
}

\section{DON D. DIESPECKER and JOHN L. MORRIS \\ University College, Wollongong, N.S.W. 2500, Australia}

Apparatus capable of transmitting signals to either a vibrator or to a light, or to both vibrator and light simultaneously, is described. The basis for encoding vibrotactile and visual stimuli is varying intensities and durations of signal.

Although the field of bisensory presentation of data has been studied for some years, it is only comparatively recently that a large number of researchers have begun to concentrate on laboratory experimentation. Generally, bisensory experiments appear to have concerned the visual and auditory senses and the skin senses have been somewhat neglected in these studies (Loveless et al, 1970).

The apparatus here described was designed to transmit signals (a) either to a single vibrator or (b) to an array of three $P$ lamps, or (c) simultaneously to both vibrator and lights. The unit's advantages are that it is compact $(10 \mathrm{x}$ $5 \times 4$ in.) and that it may be used in vibrotactile learning experiments or in bisensory experimentation when the stimuli are, e.g., visual and vibrotactile, visual and auditory, or vibrotactile and auditory. Power is supplied from a domestic mains outlet (in Australia: $240 \mathrm{~V}$ ac, $50 \mathrm{~Hz}$ ).

The cylindrical vibrator is a modification of the electromechanical transducer described by Sherrick (1965), and its components are shown in Fig. 1. This unit has been used successfully in a number of experiments over the last 6 years and has proved to be robust and reliable (Diespecker, 1968; Diespecker \& Davidson, 1971).

Low voltages (e.g., 10,15 , or $20 \mathrm{~V}$ ) are transmitted to the vibrator, which operates at $50 \mathrm{~Hz}$. The vibrator is normally taped firmly to the skin at a convenient locus, usually the volar surface of the wrist. Although vibratory stimuli can be neither seen nor heard, information may be coded by varying the available intensities and durations and transmitting these signals to the vibrator so that $\mathrm{S}$ feels and discriminates between the differing combinations of signals. Thus, it is possible, with four intensities and four durations, to encode 16 items of information, i.e., the basis of coding is $x$ intensities and $y$ durations, giving $x y$ combinations (although one of the durations in this apparatus is continuous) of signal. For example, the shortest and weakest signal may be coded as " $A$ " or as " $1 . "$ In experiments reported elsewhere, up

*We gratefully acknowledge technical assistance from $\mathrm{Mr}$. T. Barnett. The design and construction of the transmission unit was supported by the Australian Research Grants Commission. to nine stimulus elements per vibrator have been used, and it has been possible for Ss to learn the vibrotactile equivalents of the letters of the alphabet via three, four, five, or six vibrators (Diespecker, 1970).

The light source, also operated by the control unit, consists of three $\mathbf{P}$ lamps assembled in line immediately adjacent to one another. The light stimulus receives the same variable intensity-duration signals that activate the vibrator. Since most Ss in this type of experiment are unable to discriminate reliably small differences in light intensity, it is desirable to parallel a display of several lamps in line. The lamps may also be hooded or placed in a tube to heighten the visual effect.

The signaling unit diagrammed in Fig. 2 provides a variable intensity and duration signal to a visual output, $\mathrm{L}_{1}$, and to a vibrotactile output, $\mathrm{V}_{1}$. There are four degrees of intensity $\left(S_{1}\right)$ and four durations $\left(S_{2}\right)$ with provision for continuous operation. It is possible to apply any intensity-duration combination to either $L_{1}$ or $V_{1}$, or to both of these together via $S_{3}$.

$\mathrm{TR}_{1}$ provides trigger impulses which cause $\mathrm{SCR}_{1}$ and $\mathrm{SCR}_{2}$ to conduct. $\mathrm{TR}_{1}$ operates according to the time constants provided by $C_{1}$ through $C_{4}$, which are discharged by the back contacts of the operator's switch, $S_{4}$. Therefore, $S_{4}$ serves only to activate the signal to $L_{1}$ and $V_{1}$, while the duration is automatically determined. The intensity of the applied signal is obtained from a voltage divider network, $R_{1}, R_{2}$, and $R_{3}$, with provision for baseline adjustment for each intensity.

The parts are listed in Table 1.
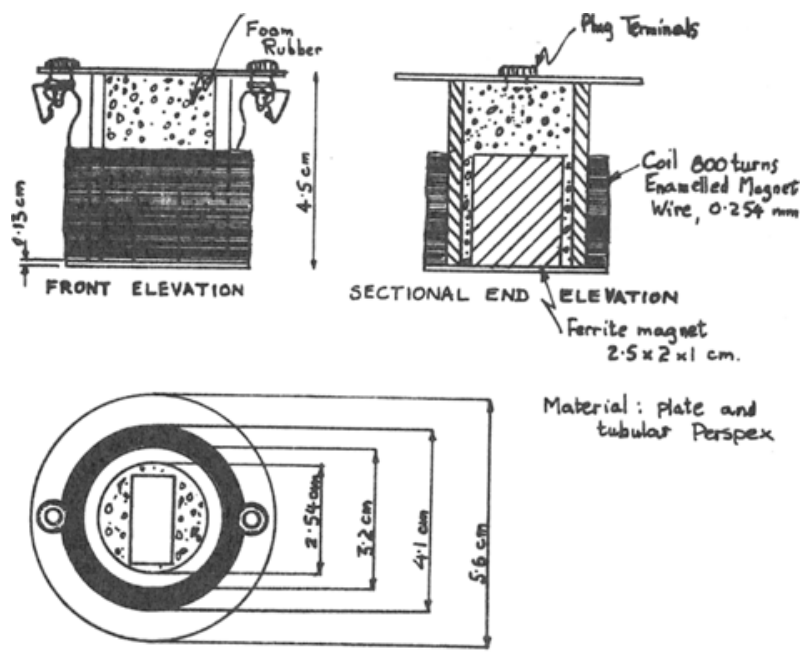

Material: plate and tubulas Perspex

Fig. 1. 


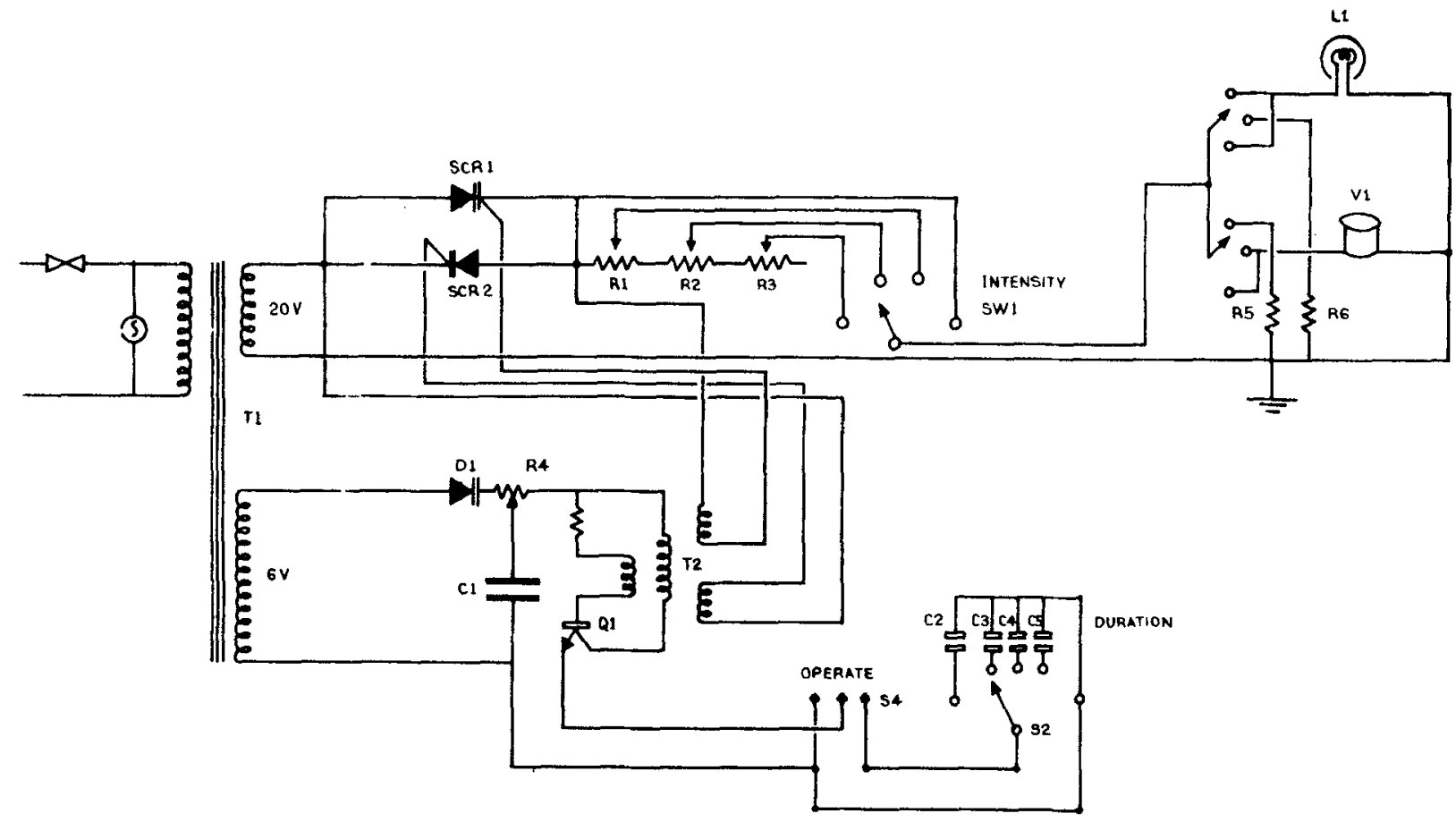

Fig. 2.

Table 1

Parts List

T1 Transformer $240 \mathrm{~V}$ Pri., $20 \mathrm{~V}$ at $1 \mathrm{a}$ and $6 \mathrm{~V}$ at $1 \mathrm{a}$

T2 Transformer LA 200 Pot Core, Pri. 800t, Feedback $300 t, 2 \times \sec 40 t$

\begin{tabular}{lrcr} 
SCR1, & GEC 6A & & \\
D1 & EM 401 & & \\
Q1 & BC 107 & \\
C1 & $100 \mu \mathrm{f}$ & $25 \mathrm{~V} \omega$ \\
C2 & $47 \mu \mathrm{f}$ & $25 \mathrm{~V} \omega$ \\
C3 & $1 \mu \mathrm{f}$ & $25 \mathrm{~V} \omega$ & \\
C4 & $5 \mu \mathrm{f}$ & $25 \mathrm{~V} \omega$ & \\
C5 & $10 \mu \mathrm{f}$ & $25 \mathrm{~V} \omega$ & \\
R1, 2,3 & $100 \Omega$ & $2 \omega$ & \\
R4 & $50 \Omega$ & $1 / 2 \omega$ & \\
R5,6 & $5 \Omega$ & $5 \omega$ & \\
V1 & Vibrator Unit (See Text) \\
L1 & P Lamp 6 V .04 amp & \\
\hline
\end{tabular}

\section{REFERENCES}

Diespecker, D. D. The effects of anchoring and practice on the learning of bidimensional vibrotactile signals. Perception \& Psychophysics, 1968, 4, 102-104.

Diespecker, D. D. Vibrotactile learning and the locus dimension Quarterly Journal of Experimental Psychology, 1970, 22, 574-582.

Diespecker, D. D., \& Davidson, J. A. Error analyses in vibrotactile code learning. Australian Journal of Psychology, $1971,23,179-183$.

Loveless, N. E., Brebner, J., \& Hamilton, P. Bisensory presentation of information. Psychological Bulletin, 1970, 73, 161-199.

Sherrick, C. E. Simple electromechanical vibration transducer. Review of Scientific Instruments, 1965, 36, 1893-1894.

(Received for publication November 7, 1972; accepted November 13,1972 .) 